\title{
Mortality from lung cancer among silicotic patients in Sardinia: an update study with 10 more years of follow up
}

P Carta, G Aru, P Manca

\begin{abstract}
Objectives-To evaluate the association between silica, silicosis and lung cancer, the mortality of 724 patients with silicosis, first diagnosed by standard chest $x$ ray film between 1964 and 1970, has been analysed by a cohort study extended to 31 December 1997.

Methods-Smoking and detailed occupational histories were available for each member of the cohort as well as the estimated lifetime exposure to respirable silica dust and radon daughters. Two independent readers blindly classified standard radiographs according to the $\mathbf{1 2}$ point International Labour Organisation (ILO) scale. Lung function tests meeting the American Thoracic Society's criteria were available for 665 patients. Standard-

and 136 matched controls). Both multivariate analyses did not show any significant association with cumulative exposure to silica or severity of silicosis, but confirmed the association between mortality for lung cancer and relatively high exposure to radon, smoking, and airflow obstruction as significant covariates.

Conclusions-The findings indicate that the slightly increased mortality for lung cancer in this cohort of silicotic patients was significantly associated with other risk factors-such as cigarette smoking, airflow obstruction, and estimated exposure to radon daughters in underground mines-rather than to the severity of radiological silicosis or to the cumulative exposure to crystalline silica dust itself. (Occup Environ Med 2001;58:786-793)
\end{abstract} ised mortality ratios (SMRs) for selected causes of death were based on the age specific Sardinian regional death rates.

Results-The mortality for all causes was significantly higher than expected (SMR $1.35,95 \%$ confidence interval (95\% CI) 1.24 to 1.46$)$ mainly due to tuberculosis (SMR 22.0) and to non-malignant chronic respiratory diseases (NMCRD) (SMR 6.03). All cancer deaths were within the expected numbers (SMR 0.93; 95\% CI 0.76 to 1.14). The SMR for lung cancer was 1.37 (95\% CI 0.98 to $1.91,34$ observed), increasing to 1.65 (95\% CI 0.98 to 2.77$)$ allowing for 20 years of latency since the first diagnosis of silicosis. Although mortality from NMCRD was strongly associated to the severity of radiological silicosis and to the extent of the cumulative exposure to silica, SMR for lung cancer was weakly related to the ILO categories and to the cumulative exposure to silica dust only after 20 years of lag interval. A significant excess of deaths from lung cancer (SMR

Institute of Occupational Medicine, University of Cagliari, Via S Georgio 12, 09124 Cagliari, Italy

P Carta

G Aru

P Manca

Correspondence to: Professor P Carta cartapl@pacs.unica.it

Accepted 12 July 2001
Keywords: silicosis; crystalline silica; lung cancer mortality

The relation between silica, silicosis, and lung cancer has been debated for a long time and, currently, still is debated. In 1987, the International Agency for Research on Cancer $(\text { IARC })^{1}{ }^{2}$ classified crystalline silica as a probable lung carcinogen in humans.

However, some editorials and reviews suggested that smoking and other occupational exposures (polycyclic aromatic hydrocarbons, radon, asbestos, and arsenic) could be confounding factors and crystalline silica could be only a possible promoter, enhancing the carcinogenic effect of cigarette smoking or of other carcinogens. ${ }^{3-7}$ In 1997, the IARC reviewed the body of epidemiological literature and stated that there was sufficient evidence for carcinogenicity of crystalline silica in humans, ${ }^{8}$ even if some difficulty in reaching this decision has been reported. ${ }^{9}$

In a recent review ${ }^{10}$ some of the main scientific uncertainties in the epidemiological evidence on the carcinogenicity of silica and silicosis were emphasised: a direct effect of silica exposure or secondary effect of silicosis; confounding by other exposures, smoking, socioeconomic class difference, and inappropriate reference population; selection and diagnostic bias among cohorts of registered silicotic patients; evidence for exposure-response lacking; and different health effects between quartz and cristobalite.

More recently an extensive re-examination of the literature on this topic was published by within the entire cohort and a nested case-control study ( 34 cases of lung cancer 
Hessel et al. ${ }^{11}$ The review focused on methodologically correct studies, including some omitted by IARC, about exposure-response analysis of workers exposed to crystalline silica and studies of workers with silicosis diagnosed at necropsy or radiographically. Contrary to the IARC statement, the authors, who followed standard criteria to assess the evidence of causality, ${ }^{12}$ concluded that the body of epidemiological literature argues against the carcinogenicity of crystalline silica and that a casual association between severity of silicosis and lung cancer is not world wide. This was supported by studies in which silicotic patients were not identified only from compensation lists.

In 1991, Carta et $a l^{13}$ assessed the mortality of all Sardinian silicotic patients radiographically diagnosed between 1964 and 1970 followed up to December 1987. Compared with the regional mortalities, the SMR for lung cancer was 1.29 (95\% confidence interval (95\% CI) 0.85 to 1.96 ), without significant trend by severity of radiological silicosis. In the nested case-control study (22 cases of lung cancer and 88 controls) analysis by International Labour Organisation (ILO) radiographic category or cumulative exposure to respirable silica $\left(\mathrm{gh} / \mathrm{m}^{3}\right)$ showed no association with lung cancer, the risk estimate for lung cancer being significantly associated with the severity of airflow obstruction, even after adjustment for cigarette smoking.

The present paper extends this previous study with 10 years more of follow up and it has been implemented by an appropriate estimation of exposure of silicotic miners and non-miners to radon daughters.

\section{Subjects and methods}

SUBJECTS

Details on subjects and exposure estimates are reported elsewhere. ${ }^{13} 14$ From about 2000 workers investigated in our Institute in Sardinia, Italy for awarding compensation, the cohort included 724 silicotic patients who had a radiographically confirmed diagnosis between 1964 and 1970. The original chest $x$ ray films, reviewed by two independent blinded readers, were classified according to the ILO 12 point classification scale of profusion, ${ }^{15}$ assigning a midpoint category when a disagreement between readers was present. However, the variability between readers never exceeded two to three points of the ILO scale.

Of the 724 radiographs showing a silicotic picture, $154(21.3 \%)$ were classified within the categories $1 / 0$ and $1 / 2,205(28.3 \%)$ within the categories $2 / 1$ and $2 / 3$, and $365(50.4 \%)$ as having a nodule profusion $3 / 2$ or higher. This included 64 films that also had some large opacities. Information on smoking habits was available for all subjects from the clinical records: 253 men $(35.1 \%)$ were never smokers and $467(64.9 \%)$ ever smokers of whom 106 $(22.6 \%)$ had smoked on average 15 or more cigarettes a day. All original spirometric tracings were revised according to the American Thoracic Society criteria ${ }^{16}$ and an acceptable test was obtained for 665 patients $(91.9 \%$ of the whole cohort). An airflow obstruction (measured as percentage of forced expired volume in 1 second divided by vital capacity $\left(\mathrm{FEV}_{1} / \mathrm{VC} \%\right)$ lower than the normal limits derived from the reference summary equations of the European Coal and Steel Community) ${ }^{17}$ was found in 307 subjects $(46.2 \%)$.

ASSESSMENT OF EXPOSURE TO SILICA DUST AND RADON PROGENY

Full employment details on individual jobs and tasks were available for the whole cohort. All subjects were employed for their lifetime only in Sardinian mines and quarries. Only 23 subjects of the entire cohort were still at work at the beginning of the follow up.

Four hundred and thirty two men (59.9\%) had worked in underground lead and zinc mines in which the silica concentration in respirable dust ranged between $2 \%$ and $29 \%$. Ninety nine were miners from metal mines of the south west of Sardinia characterised by low airborne silica concentration (median 3\%) in respirable dust, the wall rocks being dolomite and limestone with a mainly carbonatic matrix. In the west of Sardinia 333 subjects had worked in mines with high silica content (median 13\%) in respirable dust, the wall rocks being metamorphic schists with a quartz and syderite matrix. In the Sardinian brown coal (lignite) mines, 116 patients $(16.0 \%)$ had worked where the quartz content in respirable dust ranged between $2 \%$ and $10 \%$, and 176 patients $(24.3 \%)$ were granite quarrymen (range of silica concentration in respirable dust $5 \%-25 \%)$.

Previous studies ${ }^{18-20}$ and several environmental dust measurements, available since 1945 from the mining companies, provided findings for the industrial hygienists to retrospectively estimate the median exposure to respirable dust $\left(\mathrm{mg} / \mathrm{m}^{3}\right)$ for each job and task underground and at the surface, stratified by 5 year periods since the $1920 \mathrm{~s}$. Estimates were mainly based on available environmental measurements, production/year, mining technologies, and changes in ventilation and in drilling devices. An individual cumulative index of exposure to respirable dust was then calculated by summing the arithmetical products between each median dust concentration assigned to each job and task for each 5 year period and the estimated hours of exposure/year of work experienced by each subject in each workplace. The index has been reported as $\mathrm{gh} / \mathrm{m}^{3132021}$ and categorised by tertiles: $\leqslant 150,151-250$, and $>250 \mathrm{gh} / \mathrm{m}^{3}$, the tertiles comprising 316 $(43.6 \%), 270$ (37.3\%), and $138(19.1 \%)$ subjects, respectively. At the same time, based on the median quartz weight concentration in respirable dust, a cumulative index of exposure to respirable crystalline silica was also calculated in $\mathrm{gh} / \mathrm{m}^{3}$. Three categories of exposure were identified: low $\left(\leqslant 5.0 \mathrm{gh} / \mathrm{m}^{3}\right)$, intermediate $\left(5.1-10.0 \mathrm{gh} / \mathrm{m}^{3}\right)$, and high $\left(>10.0 \mathrm{gh} / \mathrm{m}^{3}\right)$, comprising $237(32.7 \%), 294(40.6 \%)$, and 193 subjects $(26.7 \%)$, respectively.

Measurements of underground $\alpha$ radiation produced by radon daughters in the main metal and coal mines in Sardinia were made 
available only since 1972 by the National Agency for Nuclear and Alternative Energy and by the Institute of Radiological Protection of the National Hydrocarbons Corporation who provided confidential reports to the mining companies. ${ }^{14}$ In metal mines in the south west of the island the average annual exposure (working time 170 hours/month and 11 months/year) during 1972-88 was 1.4 working level months (WLM)/year (maximum 3.5 WLM/year), with several estimates exceeding the recommended limit of $1.0 \mathrm{WLM} /$ year suggested by $\mathrm{NIOSH},{ }^{22}$ the early exposures to the radon progeny being higher. Cumulative exposures up to $250 \mathrm{WLM}$ were estimated for underground workers employed for a long time in these mines before 1940. In the other lead and zinc mines on the west coast, the exposure to the short lived radon decay products was much lower averaging underground about 0.12 WLM/year, with the exposure concentrations in coal mines being intermediate (median 0.6 WLM/year). Because of the short extent of environmental data we were not able to create careful individual estimates for the radon daughters exposure. However, we have identified 245 subjects of the present cohort $(33.8 \%)$, firstly engaged in mines before 1940 , whose lifetime cumulative exposure to $\alpha$ radiation was estimated as higher than 120 WLM.

\section{COHORT STUDY}

Vital status on 31 December 1997 was decided through the roster of compensated silicotic patients of the Insurance Institute and the town residence registers. Twelve men $(1.7 \%)$, known to be alive on 31 December 1987, were subsequently not traced. They were assumed to be alive at the end of follow up and contributed to person-years at risk up to the end of December 1987. Copies of death certificates were available for all the 579 dead subjects. Causes of death were revised and coded by a trained nosologist according to the ninth revision of the International Classification of Diseases (ICD-9). The standardised mortality ratios (SMRs) and their approximate $95 \%$ confidence intervals $\left(95 \%\right.$ CIs) ${ }^{23}$ were calculated for specific causes of death comparing the observed mortality with the expected numbers based on regional rates, available for each 5 year age class and calendar year during the follow up. Trends of SMRs for lung cancer and non-malignant chronic respiratory diseases (NMCRD) by ILO radiological categories of silicosis and by cumulative exposure to respirable dust were tested for significance ${ }^{24}$ in the whole cohort by different latency periods (10 and 20 years) since the diagnosis of silicosis.

The relation between deaths from lung cancer and potential risk factors for cancer was further examined with Cox's multivariate proportional hazards modelling applied to all members of the cohort with available spirometry ( $n=665)$. The Cox's regression program from SPSS for Windows ${ }^{25}$ was used. The basic time dimension was the individual period of follow up, until death or the end of the time on study. All models were stratified on age at entry (5 year strata). All explanatory variables, except ILO categories, were included as continuous variates (smoking in cigarettes a day, airflow obstruction in the percentage difference between the observed $\mathrm{FEV}_{1} / \mathrm{VC}$ and the mean predicted ratio, exposure to radon daughters in WLM, and cumulative exposure to respirable silica in $\mathrm{gh} / \mathrm{m}^{3}$ ). The regression coefficients were estimated by the maximum likelihood method and the statistical significance of the influence of each variable was assessed by the likelihood ratio test. The relative risks (RRs) of dying from lung cancer have been calculated for definite values of each variable. To simultaneously control for several factors, stepwise regression analyses (for entry $\mathrm{p}<0.05$ ) were also performed.

NESTED CASE-CONTROL STUDY

For each subject who died from lung cancer $(n=34)$ a set of four controls was randomly selected from the whole cohort, matched on the year of birth (2 years) and survival of the case.

A conditional stepwise logistic regression program $^{25}$ was used to study the association between lung cancer and several covariates (ILO categories, smoking, airflow obstruction, and exposure indices) analysed as binary or continuous variables. Calculations were performed on two sets of control patients, those who had or had not died from NMCRD.

\section{Results}

Table 1 shows the main characteristics of the whole cohort (724 silicotic patients, 13202 person-years of observation) stratified by ILO categories of radiological silicosis. The mean calendar-year of the first hire and the mean duration of employment in dusty jobs, as well as the mean cumulative exposure to respirable dust were not significantly different between groups with different nodule profusion. On the contrary, an upward trend in severity of radiological

Table 1 Main characteristics of the cohort by ILO categories of silicosis: mean (range) values

\begin{tabular}{llll}
\hline & $1 / 0-1 / 2$ & $2 / 1-2 / 3$ & $3 / 2+$ \\
\hline Subjects (n) & 154 & 205 & 365 \\
Person-years & 3036.1 & 3900.0 & 6265.9 \\
Calendar year at the first exposure to silica dust (y) & $1931.1(1926-59)$ & $1932.1(1928-60)$ & $1930.5(1924-57)$ \\
Age at the first diagnosis of silicosis (y) & $54.5(32-74)$ & $55.1(29-74)$ & $57.5(35-74)$ \\
Duration of employment in dusty jobs (y) & $24.3(2-44)$ & $24.4(3-46)$ & $23.7(3-40)$ \\
Estimated cumulative exposure to respirable dust $\left(\mathrm{gh} / \mathrm{m}^{3}\right)$ & $176.3(8-486)$ & $178.5(3-445)$ & $168.7(9-423)$ \\
Estimated cumulative exposure to respirable silica $\left(\mathrm{gh} / \mathrm{m}^{3}\right)$ & $7.3(2-24)$ & $8.1(4-28)$ & $8.6(7-30)$ \\
Estimated cumulative exposure to radon daugthers (WLM) & $97.1(0-270)$ & $95.0(0-265)$ & $89.2(0-254)$ \\
Ever smokers (\%) & 68.2 & 69.8 & 60.3 \\
Cigarettes/day $\geqslant 15(\%$ ever smokers) & 25.3 & 25.6 & 19.4 \\
Airflow obstruction $(\%)^{\star}$ & 39.9 & 45.5 & 51.5 \\
\hline
\end{tabular}

*Subjects with $\mathrm{FEV}_{1} / \mathrm{VC}<85 \%$ of mean predicted (total: 665 subjects with available spirometry). 
Table 2 SMR (95\% CI) for specific causes of death in 724 Sardinian silicotic patients (follow up 1964-97)

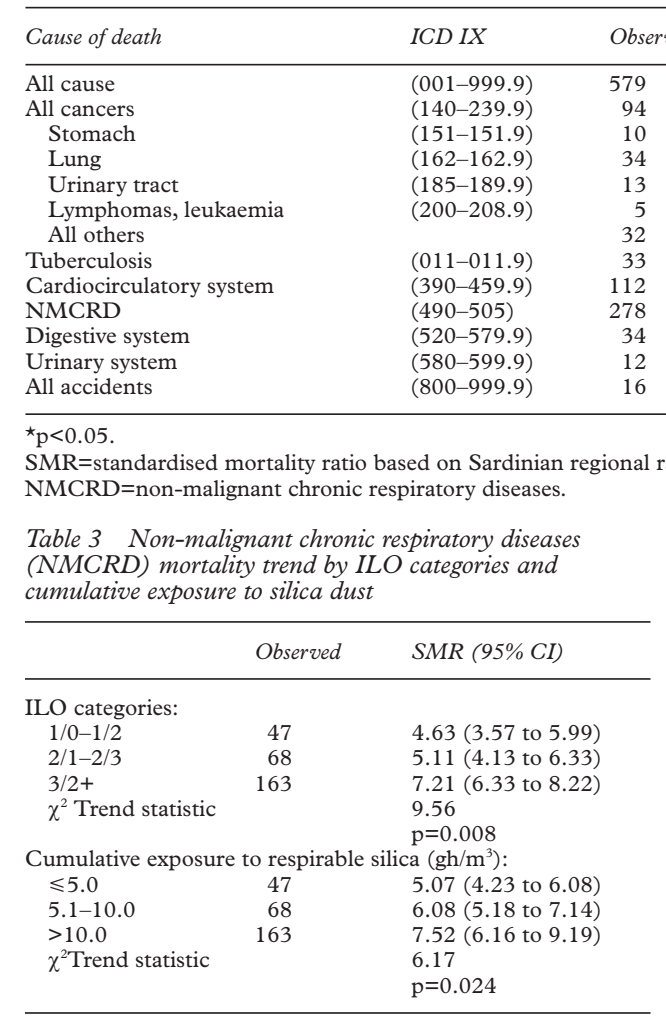

silicosis was found for the mean cumulative exposure to respirable silica dust and for the prevalence of an obstructive impairment of lung function. However the frequency of ever smokers was least $(60.3 \%)$ among patients with nodule profusion $3 / 2$ or greater. Moreover, independent from smoking, airflow obstruction was significantly correlated with the extent of the cumulative exposure to respirable dust.

The overall mortality (table 2) was significantly higher than expected (SMR 1.35, 95\% CI 1.24 to 1.46 ), although all malignant neoplasms were within the expected numbers (SMR $0.9395 \%$ CI 0.76 to 1.14 ). The mortality risk for malignant neoplasms of the lung (ICD IX 162) was higher than expected (34 observed and 24.9 expected) producing a non-significant SMR of 1.37 (95\% CI 0.98 to $1.91)$ that increased to $1.48(95 \%$ CI 1.02 to $2.16)$ and 1.65 (95\% CI 0.98 to 2.77 ) after lag intervals of 10 and 20 years since the diagnosis of silicosis. Mortality from tuberculosis was very high (SMR 22.0, 95\% CI 17.4 to 27.8 ) as was mortality from NMCRD, which was six times higher than expected (SMR 6.03, 95\% CI 5.44 to 6.69 ), confirming the well known association between silicosis and these diseases. For 12 silicotic patients the main cause of death was a non-malignant disease of the urinary system (ICD IX 580-599.9), producing an SMR of 1.97 (95\% CI 1.13 to 3.43).

Mortality for NMCRD showed significant upward trends in SMRs relative to the severity of radiological silicosis and the cumulative exposure to silica (table 3 ).

Non-significant trends for mortality from lung cancer relative to the radiological ILO categories and to the cumulative exposure to respirable silica were found in the whole cohort, but were still non-significant even with a latency of 20 years from the diagnosis (table 4).

A significant excess of deaths from lung cancer based on eight observed cancers and 3.4 expected (SMR 2.35, 95\% CI 1.20 to 4.61) was found among 99 silicotic patients (personyears 1572.0) previously employed in underground metal mines which had relatively high airborne concentrations of radon daughters (table 5). Furthermore, a significant upward trend in mortality from lung cancer was found by grouping the industries in increasing rank of exposure to radon daughters, independently from silica content in the respirable dusts.

Cigarette smoking and airflow obstruction were independently strongly related to mortality from lung cancer with significant gradients combining the two risk factors. The highest SMR (3.29, 95\% CI 2.23 to 4.83) was found among ever smokers who showed a spirometric obstructive impairment at the time

Table 4 Lung cancer mortality trend by ILO categories and cumulative exposure to respirable silica dust, by latency since first diagnosis of silicosis

\begin{tabular}{|c|c|c|c|c|c|c|}
\hline & \multicolumn{2}{|c|}{ No latency } & \multicolumn{2}{|c|}{10 y latency } & \multicolumn{2}{|c|}{20 y latency } \\
\hline & $\mathrm{Obs}^{*}$ & $S M R(95 \% C I)$ & $O b s^{*}$ & $S M R(95 \% C I)$ & $\mathrm{Obs}^{*}$ & $\operatorname{SMR}(95 \% C I)$ \\
\hline \multicolumn{7}{|l|}{ ILO categories: } \\
\hline $1 / 0-1 / 2$ & 7 & 1.23 (0.59 to 2.57$)$ & 6 & 1.39 (0.63 to 3.10$)$ & 3 & $1.46(0.47$ to 4.49$)$ \\
\hline $2 / 1-2 / 3$ & 11 & $1.50(0.83$ to 2.70$)$ & 8 & $1.45(0.73$ to 2.89$)$ & 4 & $1.49(0.56$ to 3.95$)$ \\
\hline $3 / 2+$ & 16 & $1.34(0.83$ to 2.19$)$ & 13 & $1.55(0.90$ to 2.66$)$ & 7 & $1.91(0.92$ to 3.95$)$ \\
\hline$\chi^{2}$ Trend statistic & & NS & & NS & & NS \\
\hline \multicolumn{7}{|c|}{ Cumulative exposure to respirable silica: } \\
\hline$\leqslant 5.0\left(\mathrm{gh} / \mathrm{m}^{3}\right)$ & 11 & 1.55 (0.59 to 2.57$)$ & 7 & $1.43(0.68$ to 2.98$)$ & 4 & $1.46(0.47$ to 4.49$)$ \\
\hline $5.1-10.0\left(\mathrm{gh} / \mathrm{m}^{3}\right)$ & 13 & $1.25(0.73$ to 2.15$)$ & 11 & $1.44(0.80$ to 2.58$)$ & 5 & $1.43(0.60$ to 3.42$)$ \\
\hline$>10.0\left(\mathrm{gh} / \mathrm{m}^{3}\right)$ & 10 & $1.35(0.73$ to 2.51$)$ & 9 & $1.60(0.84$ to 3.05$)$ & 5 & $2.08(0.88$ to 4.91$)$ \\
\hline$\chi^{2}$ Trend statistic & & NS & & NS & & NS \\
\hline
\end{tabular}

^Obs=Observed deaths. 
Table 5 Lung cancer mortality trend by industry according to exposure to radon daugters $†$

\begin{tabular}{|c|c|c|c|c|c|c|}
\hline Industry & $n$ & Person-years & Obs $\neq$ & $\operatorname{Exp} \neq$ & $S M R$ & $95 \% C I$ \\
\hline Granite quarries & 176 & 2963.7 & 5 & 5.6 & 0.89 & 0.37 to 2.14 \\
\hline Metal mines $\rrbracket$ & 333 & 6579.9 & 14 & 11.7 & 1.20 & 0.71 to 2.02 \\
\hline Coal mines & 116 & 2086.4 & 7 & 4.2 & 1.67 & 0.80 to 3.47 \\
\hline \multirow{2}{*}{ Metal mines } & 99 & 1572.0 & 8 & 3.4 & 2.35 & 1.20 to $4.61^{\star}$ \\
\hline & & & & $\begin{array}{l}\text { Poisson } \chi^{2} \text { trend } \\
\text { statistic }\end{array}$ & $3.87^{\star}$ & \\
\hline
\end{tabular}

${ }^{\star} \mathrm{p}<0.05$.

†See text: Assessment of exposure to silica dust and radon progeny.

$\ddagger$ Obs=observed deaths; Exp=expected deaths.

Metal mines with low exposure to radon daughters (mean=0.12 WLM/y)

\Metal mines with relatively high exposure to radon daughters (mean=1.43 WLM/y).

of the first diagnosis of silicosis (data not shown in a table).

Regression coefficients and estimated relative risks of dying from lung cancer derived from the Cox's proportional hazard model are reported in table 6 . The number of cigarettes smoked a day, the severity of airflow obstruction, and the cumulative exposure to radon daughters were the only significant explanatory variables for deaths from lung cancer in this study. Relative risks associated with exposure to silica dust and to the severity of radiological silicosis were not significantly different from unity. The coefficient of exposure to radon daughters remained significant at the 0.05 level even when smoking and airflow obstruction were included as covariates in the stepwise model.

The nested case-control study confirmed the significant association between mortality from lung cancer and the estimated cumulative exposure to radon daughters (OR 2.21, 95\% CI 1.01 to 4.85 for exposures higher than 120 WLM) also after controlling for cigarette smoking (OR 2.86, 95\% CI 1.24 to 6.75 , comparing ever smokers with non-smokers) and airflow obstruction (OR 3.86, 95\% CI 1.72 to 8.70 for patients with $\mathrm{FEV}_{1} / \mathrm{VC}$ ratio $<85 \%$ of mean predicted).

No more improvement in significance of the stepwise model was found including the severity of radiological silicosis (OR 1.06, 95\% CI 0.80 to 4.24 for categories $3 / 2+$ ) or the cumulative exposure to respirable silica dust (OR 1.30, $95 \%$ CI 0.71 to 2.68 for exposures higher than $\left.10 \mathrm{gh} / \mathrm{m}^{3}\right)$. Results did not change when smoking, airflow obstruction, and exposure to silica and radon were analysed as continuous variables.

Using controls who died from NMCRD did not substantially change the results of the nested case-control study.

\section{Discussion}

As in our previous follow up study, ${ }^{13}$ the findings of this updated study mostly do not show a significantly consistent association between severity of radiological silicosis or cumulative exposure to crystalline silica and lung cancer mortality, after controlling for smoking and other covariates. Tobacco smoking, airflow obstruction, and a relatively high exposure to radon daughters experienced in some underground mines were the most significant predictors of lung cancer in this study.

However, the roughly doubling of risk of lung cancer found for the highest ILO category (SMR 1.91; 95\% CI 0.92 to 3.95) and for the highest stratum of cumulative exposure to silica (SMR $2.0895 \%$ CI 0.88 to 4.91 ) for 20 years of latency (table 4), although not significant, suggest that the role of these variables should not be completely dismissed.

The significant trend found for mortality from NMCRD, mainly silicosis and chronic obstructive lung diseases, by cumulative exposure to respirable silica proves the consistency of the environmental dust measurements and estimates and the validity of the exposure index. Furthermore, a relation between increasing cumulative exposure to respirable silica and increasing severity of radiological silicosis has been found in our study, suggesting that silicosis as a reliable marker of high exposure to crystalline silica.

Human exposure-response studies show that there is a strong relation between cumulative exposure to silica and the risk of silicosis of severity $1 / 1$ or greater ${ }^{26-30}$ as well as between increasing burden of crystalline silica retained in the lung and increasing pathological grade of silicosis. $^{3132}$

Table 6 Regression coefficients and risk estimates of dying for lung cancer by smoking, airflow obstruction, cumulative exposure to radon daughters and silica (continuous variables) and by ILO radiological categories of silicosis (categorical variable) based on the Cox's multiple regression analysis of 665 silicotics with available spirometry (34 lung cancer deaths)

\begin{tabular}{|c|c|c|c|c|c|c|}
\hline Variables & $\beta^{\star}$ & $S E$ & $p$ Value & & $R R t$ & $95 \% C I$ \\
\hline Smoking (cigarettes/day) & 0.0468 & 0.0202 & 0.0208 & RR per 10 cigarettes/day & 1.60 & 1.07 to 2.37 \\
\hline Airflow obstruction $\left(\mathrm{FEV}_{1} / \mathrm{VC}-\right.$ predicted $) \times 100$ & 0.0491 & 0.0125 & 0.0001 & RR per $20 \%$ below predicted & 2.67 & 1.63 to 4.36 \\
\hline Radon daughters exposure (WLM) & 0.0037 & 0.0014 & 0.0112 & RR per $100 \mathrm{WLM}$ & 1.45 & 1.10 to 1.90 \\
\hline Cumulative exposure to respirable $\mathrm{SiO}_{2}\left(\mathrm{gh} / \mathrm{m}^{3}\right) \ddagger$ & 0.0026 & 0.0412 & 0.9491 & $\mathrm{RR}$ per $10 \mathrm{gh} / \mathrm{m}^{3}$ & 1.03 & 0.46 to 2.30 \\
\hline Severity of radiological silicosis & 0.0259 & 0.2281 & 0.9093 & & & \\
\hline \multirow[t]{3}{*}{ (ILO category) $\neq \$} & & & & RR for category $1 / 0-1 / 2$ & 1.00 & \\
\hline & & & & RR for category $2 / 1-2 / 3$ & 1.03 & 0.66 to 1.61 \\
\hline & & & & $\mathrm{RR}$ for category $3 / 2+$ & 1.05 & 0.43 to 2.57 \\
\hline
\end{tabular}

${ }^{*} \beta=$ regression coefficient.

$+\mathrm{RR}=$ relative risk.

$\ddagger$ Variables that did not enter the stepwise model.

CCategorical variable included as $0,1,2$. 
Because until 1970 our institute was the only regional referral centre of the National Insurance Institute for Occupational Diseases for a standardised diagnosis of pneumoconiosis among claimants who were workers exposed to dust, the studied cohort includes almost all incident cases of radiologically confirmed silicosis in Sardinia during 1964-70. Moreover, the diagnosis was only based on blinded reanalysis of original radiographs that were compared with the ILO reference chest films and classified according to the ILO categories ${ }^{12}$ unaware of lung function, smoking, and dust exposure. Thus, our cohort seems relatively free from relevant selection or diagnostic bias and represents a well defined group of silicotic patients who had previously experienced very large exposures to silica dust. Full individual work and smoking history was available in details for all cohort members at entry to the follow up so that it was possible to estimate an individual cumulative exposure to dust and radon and to control for confounding by smoking.

Unfortunately we were unable to simultaneously follow up the internal reference group of non-silicotic cases with the same detailed information on smoking and occupational exposure to compare the relative risk of lung cancer found among the two groups.

Coal miners included in this cohort had worked only in a Sardinian mine of lignite, ${ }^{33}$ a low rank type of coal, with a $2 \%-10 \%$ quartz in the respirable dusts, which yielded a pneumoconiotic radiological picture mainly characterised by rounded opacities, such as silicosis or anthracosilicosis, ${ }^{18}{ }^{19}$ completely different from the typical simple coal worker's pneumoconiosis of miners employed in high rank coal mines.

In studies of silicotic patients a roughly doubling of risk of lung cancer has been collectively described. ${ }^{34}$. However, most of these studies are based only on compensation lists that make interpretation of results difficult because of confounding by smoking, other exposure, respiratory impairment, and uncertainty of diagnosis. Furthermore, in several studies a stronger relative risk of lung cancer and a stronger relation between exposure to silica and lung cancer has been reported among silicotic patients compared with non-silicotic patients. $^{35}$

However, two necropsy studies of South African gold miners ${ }^{36} 37$ did not find any relation between lung cancer and the presence of parenchymal silicosis after adjustment for smoking.

Despite some problems with the application of chest radiographs in epidemiological studies (low sensitivity compared with silicosis confirmed at necropsy, variability between readers, disease misclassification), the ILO standardised radiological method, and its classification as nodule profusion, is the only well consolidated method for detecting and categorising silicosis in exposed workers. Results are inconsistent among studies in which silicosis was assessed radiographically, either by only one chest radiograph at the beginning of follow up or by serial radiographs. Some found a significantly higher relative risk of lung cancer in silicotic compared with non-silicotic patients, ${ }^{38-44}$ whereas others studies ${ }^{13}{ }^{45-49}$ found only weak differences in mortality from lung cancer between silicotic and non-silicotic patients, ${ }^{48}$ contradictory results between different working trades, ${ }^{45}$ or no association ${ }^{134647} 49$ between silicosis and lung cancer after controlling for smoking and exposure to silica dust.

Only a few studies have analysed the risk of lung cancer by increasing category of radiological silicosis ${ }^{13} 394950$ with contradictory results: two of them ${ }^{39} 50$ found clear gradients for lung cancer, whereas in the others no consistent relation was found between risk of dying from lung cancer and either severity of radiological silicosis or exposure to silica. ${ }^{139}$

The assessment of a dose-response relation, independently of the severity of silicosis, is of critical importance for an association between lung cancer and cumulative exposure to silica. In workers in the diatomaceous earth industry $^{51}$ exposed to respirable dust with about $10 \%-25 \%$ of cristobalite, an increasing risk for NMRD and for lung cancer was described with an index for increasing cumulative exposure to crystalline silica. Significant gradients were found for NMRD whereas less convincing results were found for lung cancer in a study ${ }^{52}$ that updated the same cohort. A positive trend was also reported among South African gold miners exposed to quartz, ${ }^{36}$ but the possibility of a confounding effect from radon daughters was suggested, as the increased intensity of exposure to dust was correlated with a concurrent potentially increased exposure to $\alpha$ radiations underground. However, no consistent association between exposure to respirable dust and lung cancer was found in the absence of silicosis in other recent studies. ${ }^{42} 43454753-55$

In the present study, results from both the Cox's proportional hazard modelling and the nested case-control study were comparable. Cigarette consumption was the most significant explanatory variable of lung cancer mortality which had increased. Apart from smoking habits the severity of obstructive impairment as detected at entry had also increased.

After allowing for these variables, a residual significant effect of relatively high cumulative exposure to radon daughters experienced in underground mines still existed.

On the contrary, neither the cumulative exposure to silica dust nor the severity of radiological silicosis entered the stepwise regressions ( $p>0.05)$.

The exclusion of controls who died from NMCRD in the nested case-control study would have had the effect of biasing the odds ratios upward for silica and for silicosis relative to lung cancer. The negative results found for both silica and silicosis despite this potential bias, further support our conclusions.

Thus, short lived radon decay products together with smoking could share the role of 
initiating the carcinogenic process; the cumulative exposure to crystalline silica and the severity of silicosis, by itself, do not seem to be independent risk factors for lung cancer in the present study. These results are similar to those we found in a previous mortality study ${ }^{14}$ of two cohorts of active metal miners, still at work in 1973 and followed up to the end of December 1988, who experienced different exposure to crystalline silica and radon daughters in two different Sardinian lead and zinc mines.

The exposure to short lived radon decay products, even at relatively low levels, has been suggested as one of the main likely causes of the excess of lung cancer found in several studies of underground miners ${ }^{1437425657}$ or of registered silicotic patients. ${ }^{49}$

The association between airflow obstruction and increased risk of lung cancer has been supported by several population based studies ${ }^{58-63}$ and mortality studies of silicotic patients and metal miners. ${ }^{1314}$ All these studies showed increased risk of lung cancer, independently of age and smoking, among subjects whose baseline spirometry at entry in the follow up indicated airflow limitation. The exact mechanism underlying this association is still not known, although it has been suggested that lung tissue damage leading to airway obstruction might enhance the effect of carcinogens or might be the expression of the inability to handle an oxidative insult. ${ }^{61}$ Smoking and chronic exposure to dust and gases cause inflammatory injury to airways with consequent imbalance of inflammatory mediators and humoral protection (oxidant/antioxidant) contemporaneously leading to progressive airway obstruction and clearing impairment of inhaled particles, increasing the residence time of active carcinogens in the lung. Fibrogenic dusts-such as silica-might cooperate by also impairing the lymphatic clearance of particles because of the lymphatic obstruction by macrophages containing silica or silica alone. ${ }^{64}$ Silicosis, particularly if associated with chronic airways obstruction, is likely to be the worst condition in this context. ${ }^{13}$

1 International Agency for Research on Cancer. IARC monographs on the evaluation of the carcinogenic risk of chemicals to humans. Vol 42. Silica and some silicates. Lyon: IARC, 1987

2 International Agency for Research on Cancer. IARC monographs on the evaluation of carcinogenic risk to humans. Vols 1-42, suppl 7. Overall evaluations of carcinogenicity: an updating of IARC monographs. Lyon: IARC, 1987.

3 Heppleston AG. Silica, pneumoconiosis, and carcinoma of the lung. Am F Ind Med 1985; 7:285-94.

4 McDonald JC. Silica, silicosis, and lung cancer. $B r$ F Ind Med 1989;46:289-91.

5 Pairon JC, Brochard P, Jaurand MC, et al. Silica and lung cancer: a controversial issue. Eur Respir f 1991;4:730-44.

6 Agius R. Is silica carcenogenic? Occup Med 1992;42:50-2. Craighead JE. Do silica and asbestos cause lung cancer? Arch Pathol Lab Med 1992;116:16-20.

8 International Agency for Research on Cancer. IARC monographs on the evaluation of the carcinogenic risk of chemical to humans. Vol 68. Silica, some silicates, coal dust and para-amid fibrils. Lyon: IARC, 1997.

9 McDonald C, Cherry N. Crystalline silica and lung cancer: the problem of conflicting evidence. Indoor Built Environment 1999;8:121-6.

10 Soutar CA, Robertson A, Miller BG et al. Epidemiological evidence on the carcinogenicity of silica: factors in scientific judgement. Ann Occup Hyg 2000;44:3-14.

11 Hessel PA, Gamble JF, Gee JBJ, et al. Silica, silicosis, and lung cancer: a response to a recent working group report. $\mathcal{F}$ Occup Environ Med 2000;42:704-20.

12 Hill AB. The environment and disease: association or causation? Proc R Soc Med 1965;58:295-300.
13 Carta P, Cocco PL, Casula D. Mortality from lung cancer among Sardinian patients with silicosis. Brf Ind Med 1991; 48:122-9.

14 Carta P, Cocco PL, Picchiri GF. Lung cancer mortality and airways obstruction among metal miners exposed to silica and low levels of radon daughters. Am F Ind Med 1991;25: 489-506.

15 International Labour Office. Guidelines for the use of ILO international classification of radiographs of pneumoconiosis. Geneva: ILO, 1980. (Occupational Safety and Health series No 22.)

16 American Thoracic Society. Standardization of spirometry: 1987 update. Am Rev Respir Dis 1987;136:1285-98.

17 Quanjer PH. Standardized lung function testing. Report of working party on stardardization of lung function tests of the European Community for Coal and Steel. Bull Eur Physiopathol Respir 1983;19(suppl 5):1-94.

18 Casula D. Aspetti diagnostici della silicosi (con particolare riguardo alla situazione in Sardegna). Proceedings of the 2nd national conference on silicosis. Cagliari: 1965;1:25-60.

19 Casula D, Cherchi P, Sanna Randaccio F, et al. In: Valdes P, ed. Piano di lotta contro la silicosi e le altre pneumoconiosi di particolare importanza per la Sardegna. Cagliari: 1982;1:1particola.

20 Casula D, Carta P, Sanna Randaccio F. A 6 year longitudinal study of Sardinian metalliferous miners. Proceedings of the 6th international conference on pneumoconiosis. Bochum. Geneva: International Labour Organization, 1983;2:110712.

21 Rogan JM, Attfield MD, Jacobsen M, et al. Role of dust in the working environment in development of chronic bronchitis in British coal miners. Br F Ind Med 1973;30:217-26.

22 National Institute for Occupational Safety and Health (NIOSH). A recommended standard for occupational exposure to radon progeny in underground mines. Washington, DC: US to radon progeny in underground mines. Washington, DC: US Department of Health and Human Services, DHHS (NIOSH)

23 Rothman KJ. Modern epidemiology. Boston: Little Brown, 1986

24 Breslow NE, Day NE. Statistical methods in cancer research. Vol II the analysis of cohort studies. Lyon: International Agency for Research on Cancer, 1987.

25 Norusis MJ. SPSS for windows. Cichago: SPSS, 1993

26 Hnizdo E, Sluis-Cremer GK. Risk of silicosis in a cohort of white South African gold miners. Am $\mathcal{F}$ Ind Med 1993;24:447-57.

27 Rice FL, Stayner LT. Assessment of silicosis risk for occupational exposure to crystalline silica. Scand 7 Work Environ Health 1995;21 (suppl 2):87-90.

28 Steenland K, Brown D. Silicosis among gold miners: exposure-response analyses and risk assessment. Am F Public Health 1995;85:1372-7.

29 Miller BG, Hagen S, Love RG et al. Risk of silicosis in coalworkers exposed to unusual concentrations of respirable quartz. Occup Environ Med 1998;55:52-8.

30 Greaves IA. Not-so simple silicosis: a case for public health action. Am f Ind Med 2000;37:245-51.

31 Nagelschmidt $G$. The relation between lung dust and lung pathology in pneumoconiosis. Br f Ind Med 1960;17:247-

32 Mossman BT, Churg A. Mechanisms in the pathogenesis of asbestosis and silicosis. Am 7 Respir Crit Care Med 1998; 157:1666-80.

33 Carta P, Aru G, Barbieri MT, et al. Dust exposure, respiratory symptoms, and longitudinal decline of lung function in young coal miners. Occup Environ Med 1996;53:312-19.

34 Smith AH, Lopipero PA, Barroga VR. Meta-analysis of studies of lung cancer among silicotics. Epidemiology 1995; 6:617-24

35 Checkoway H, Franzblau A. Is silicosis required for silica-associated lung cancer? Am f Ind Med 2000;37:2529.

36 Hessel PA, Sluis-Cremer GK, Hnizdo E. Silica exposure, silicosis and lung cancer: a necropsy study. Br f Ind Med 1990;47:4-9.

37 Hnzido E, Sluis-Cremer GK. Silica exposure, silicosis and lung cancer: a mortality study of South African gold miners. Br f Ind Med 1991;48:53-60.

38 Amandus HE, Castellan RM, Shy C et al. Re-evaluation of silicosis and lung cancer in North Carolina dusty trades workers. Am f Ind Med 1992;22:147-53.

39 Cherry NM, Burgess G, McNamee R, et al. Initial finding from a cohort mortality study of British pottery workers. Appl Occup Environ Hyg 1995;10:1042-5.

40 Dong P, Xu G, Sun Y, et al. Lung cancer among workers exposed to silica dust in Chinese refractory plants. Scand $\mathcal{F}$ Work Environ Health 1995;21 (suppl 2):69-72.

41 Meijers JMM, Swaen GMH, Slangen JJM. Mortality and lung cancer in ceramic workers in the Netherlands: preliminary results. Am F Ind Med 1996;30:26-30.

42 Hnzido E, Murray J, Klempman S. Lung cancer in relation to exposure to silica dust, silicosis and uranium production in South African gold miners. Thorax 1997;52:271-5.

43 de Klerk NH, Musk AW. Silica, compensated silicosis, and lung cancer in western Australian gold miners. Occup Environ Med 1998;55:243-8.

44 Finkelstein MM. Radiographic silicosis and lung cancer risk among workers in Ontario. Am ₹ Ind Med 1998;34:244-51.

45 McLaughlin JK, Jing-Qiong C, Dosemeci M, et al. A nested case-control study of lung cancer among silica exposed workers in China. Br f Ind Med 1992;49:167-71. 
46 Hua F, Xueqi G, Xipeng J, et al. Lung cancer among tin miners in southeast China: silica exposure, silicosis, and cigarette smoking. Am 7 Ind Med 1994;26:373-81.

47 Cherry NM, Burgess GL, Turner S, et al. Crystalline silica and risk of lung cancer in the potteries. Occup Environ Med 1998;55:779-85.

48 Checkoway H, Hughes JM, Weill $\mathrm{H}$, et al. Crystalline clinical exposure, radiological silicosis, and lung cancer mortality in diatomaceous earth industry workers. Thorax 1999;54:56-9.

49 Chan CK, Leung CC, Tam CM, et al. Lung cancer mortality among a cohort of men in a silicotic register. $\mathcal{F}$ Occup Environ Med 2000;42:69-75.

$50 \mathrm{Ng}$ TP, Chan SL, Lee J. Mortality of a cohort of men in a silicosis register: further evidence of an association with lung cancer. Am f Ind Med 1990;17:163-71.

51 Checkoway H, Heyer NJ, Demers PA, et al. Mortality among workers in the diatomaceous earth industry. $\mathrm{Br} F$ Ind Med 1993:50:586-97.

52 Checkoway H, Heyer NJ, Seixas NS, et al. Dose-response association of silica with non-malignant respiratory disease and lung cancer in the diatomaceous earth industry. $A m \mathcal{F}$ Epidemiol 1997:145:680-8.

53 Steenland K, Brown D. Mortality study of gold miners exposed to silica and non-asbestiform amphibole minerals an update with 14 more years of follow up. Am F Ind Med 1995;27:217-29.

54 Reid PJ, Sluis-Cremer GK. Mortality of white South African gold miners. Occup Environ Med 1996;53:11-16.

55 Ulm K, Walschulzik B, Ehnes $\mathrm{H}$ et al. Silica dust and lung cancer in the German stone, quarrying, and ceramics industries: results of a case-control study. Thorax 1999;54 347-51.
56 Battista G, Belli S, Carboncini F, et al. Mortality among pyrite miners with low-level exposure to radon daughters. Scand $\mathcal{F}$ Work Environ Health 1988;14:280-5.

57 Kusiak RA, Springer J, Ritchie AC, et al. Carcinoma of the lung in Ontario gold miners: possible aetiological factors. $B r \mathcal{F}$ Ind Med 1991;48:808-17.

58 Cohen BH, Graves CG, Levy DA, et al. A common familial component in lung cancer and chronic obstructive pulmonary disease. Lancet 1977; ii:523-6.

59 Skillrud DM, Offord KP, Miller D. Higher risk of lung cancer in chronic obstructive pulmonary disease: a prospective, matched, controlled study. Ann Intern Med 1986;105: 503-7.

60 Anthonisen NR. Prognosis in chronic obstructive pulmonary disease: results from multicenter clinical trials. $\mathrm{Am}$ Rev Respir Dis 1987;140:S95-9.

61 Tockman MS, Anthonisen NR, Wright EC, et al. Airways obstruction and the risk for lung cancer. Ann Intern Med 1987; 106:512-18.

62 Kuller LH, Ockene J, Meilahn E, et al. Relation of forced expiratory volume in one second $\left(\mathrm{FEV}_{1}\right)$ to lung cancer mortality in the multiple risk factor intervention trial (MRFIT). Am f Epidemiol 1990;132:265-74.

63 Nomura A, Stemmermann GN, Chyou PH, et al. Prospective study of pulmonary function and lung cancer. Am Rev Respir Dis 1991;144:307-11.

64 Guidotti TL, Coley BD, Goldsmith DF. Silica exposure and intrathoracic lymphatic changes. In: Goldsmith DF, Winn DM, Shy CM, eds. Silica, silicosis and lung cancer. Controversy in occupational medicine. New York: Praeger, 147-55.

\section{7th European Forum on Quality Improvement in Health Care}

\section{1-23 March 2002 \\ Edinburgh, Scotland}

We are delighted to announce this forthcoming conference in Edinburgh. Authors are invited to submit papers (call for papers closes on Friday 5 October 2001) and delegate enquiries are welcome.

The themes of the Forum are:

- Leadership, culture change, and change management

- Achieving radical improvement by redesigning care

- Health policy for lasting improvement in health care systems

- Patient safety

- Measurement for improvement, learning, and accountability

- Partnership with patients

- Professional quality: the foundation for improvement

- Continuous improvement in education and training

- People and improvement.

Presented to you by the BMJ Publishing Group (London, UK) and Institute for Healthcare Improvement (Boston, USA). For more information contact: quality@bma.org.uk or look at the website www.quality.bmjpg.com. Tel: +44 (0)20 7383 6409; fax: +44 (0)20 73736869 .

It has come to the attention of the editors of Occupational and Environmental Medicine and Occupational Medicine that there has been inadvertent duplicate publication in our two journals of two papers based on the same subject group and which have significant overlap. The references for these two papers are:

Exposure to benzene in urban workers: environmental and biological monitoring of traffic police in Rome. Crebelli R, Tomei F, Zijno A, et al. Occup Environ Med 2001;58:165-71.

Environmental and biological monitoring of traffic wardens from the City of Rome. Tomei F, Ghittori S, Imbriani M, et al. Occup Med 2001;51:198-203.

We have contacted the Committee on Publication Ethics who suggested the publication of this notice in our journals.

Anne Cockcroft, Editor, Occupational and Environmental Medicine Jerry Beach, Editor, Occupational Medicine 